\title{
Water Relations, Hormonal Level, and Spectral Reflectance of Gerbera jamesonii Bolus Subjected to Chilling Stress
}

\author{
R. Savé, J. Peñuelas, I. Filella, and C. Olivella \\ Departament de Tecnologia Hortícola, Centre de Cabrils, Institut de Recerca i Tecnología Agroalimentanes, \\ Carretera de Cabrils s/n, 08348 Cabrils, Barcelona, Catalunya, Spain
}

Additional index words. abscisic acid, cytokinins, chlorophyll content, leaf water potential, leaf water loss, red edge, reflectance, root hydraulic resistance, stomatal conductance

\begin{abstract}
One-year-old gerbera plants subjected to 1 night at $5 \mathrm{C}$ had reduced leaf water losses and chlorophyll content and increased root hydraulic resistance, but stomatal conductance and leaf water potential did not change. After 3 nights, leaf water potential had decreased and leaf reflectance in the visible and the near-infrared had increased. Similarly, abscisic acid (ABA) in leaves had increased and cytokinins (CK) in leaves and roots had decreased, but ABA levels in roots did not change. After 4 days at $20 \mathrm{C}$, root hydraulic resistance, reflectance and leaf water loss returned to their initial values, but leaf water potential and chlorophyll content remained lower. Leaf ABA levels reached values lower than the initial, while root $\mathrm{ABA}$ and leaf $\mathrm{CK}$ levels retained the initial values. These data suggest that in the gerbera plants studied, 3 nights at 5C produced a reversible strain but otherwise plants remained uninjured, so this gerbera variety could be cultured with low energetic inputs under Mediterranean conditions. The results may indicate that ABA and CK were acting as synergistic signals of the chilling stress. Spectral reflectance signals seemed to be useful as plant chilling injury indicators at ground level.
\end{abstract}

Chilling injury has been defined as injury at cold temperatures above the freezing point of water. For many tropical and subtropical species damage occurs with exposure to a range of temperatures between 0 and 15C (Lyons, 1973; Markhart, 1986). Plants subjected to chilling stress exhibit direct injury as water-soaked leaves or necrosis resulting from a loss of membrane semipermeability and leakage of electrolytes into free space. Secondary symptoms include leaf water deficits, decreases in photosynthetic rates, and several other metabolic changes (Levitt, 1980). Leaf water deficits can result from a reduction in root water uptake (Ramos and Kaufmann, 1979) and loss of stomatal control (Earnus et al., 1983).

Hormones, particularly abscisic acid (ABA), play an important role in the adaptation of plants to environmental stresses (Davies and Zhang, 1991) by reducing water losses, an important mechanism of water stress avoidance (Turner, 1986). The role of ABA in the regulation of stomatal aperture in chilled plants remains controversial (Pardossi et al., 1992), and a synergistic effect of several hormones on. the fine control of stomatal movements has been suggested as the basis of an integrated response to this abiotic stress (Mansfield, 1987).

There are some data on frost damage detection by remote sensing using satellite images. Gilabert et al. (1990) have found important qualitative variations in the reflectance spectra of plants after suffering frost stress with a decrease in the near-infrared attributable to the irreversible modification in internal structure due to cold damage, and there are also changes described in the visible region associated with reduced photosynthetic activity

Received for publication 1 Mar. 1994. Accepted for publication 3 Jan. 1995. This research was partially supported by the research program EEC DG-VI PL 900165 , by a grant AGR90-458 from CICYT (Spain), by CIRIT (Catalunya, Spain), and by la Caixa de Barcelona. A fellowship FPI (Spain) to I. Fiiella is gratefully acknowledged. We thank Xavier Carbonell, José Montero, Carme Biel, and David Serra for their assistance and J. Sanchez Bravo for helpful comments and criticism on analytical determinations. The cost of publishing this paper was defrayed in part by the payment of page charges. Under postal regulations, this paper therefore must be hereby marked advertisement solely to indicate this fact.
(Schanda, 1986). But there are no data, as far as we know, on spectral response to chilling.

Gerbera jamesonii Bolus is a species sensitive to low temperatures (Berniger, 1979; Savé and Matas, 1990; Savé et al., 1992). The aim of the present study was to assess the physiology of chilled gerbera plants and its relationship with the spectral signals to evaluate the usefulness of spectroradiometry as an early indicator of chilling stress.

\section{Material and Methods}

Experiments were performed on 1-year-old plants of Gerbera jamesonii Bolus ' $\mathrm{G} 1$ ' obtained from in vitro culture and grown in 25 -cm-diameter pots in a greenhouse. A mixture of 12 perlite :5 pine bark :3 peat (v/v) was used as a growth medium that was irrigated daily with a solution containing 9.12 meq.liter ${ }^{-1} \mathrm{NO}_{3}^{-}$, 0.96 meq.liter ${ }^{-1} \mathrm{PO}_{4} \mathrm{H}^{-2}, 8.02$ meq.liter ${ }^{-1} \mathrm{SO}_{4}^{-2}, 5.44$ meq.liter ${ }^{-1} \mathrm{~K}+$, 8.50 meq.liter ${ }^{-1} \mathrm{Ca}^{+2}$, 3.37 meq.liter ${ }^{-1} \mathrm{Mg}^{+2}$ and $0.25 \mathrm{~g} \cdot$ liter $^{-1}$ of micronutrients.

Twenty plants were acclimatized in a growth chamber for 1 week before use. Photosynthetic photon flux at the top of the plants was $300 \mu \mathrm{mol} \cdot \mathrm{m}^{-2} \cdot \mathrm{s}^{-1}$. Photoperiod was $13 \mathrm{~h}$, relative humidity $70 \% \pm 5 \%$, and temperature $20 \pm 2 \mathrm{C}$. Chilling treatments consisted of 3 nights at $5 \mathrm{C}$ and subsequent recovery at 20C for 4 days.

Plant water relationships and spectral measurements. Leaf gas exchange measurements were conduced on intact top canopy leaves of similar physiological stage with a model portable infrared gas analysis porometer (LI-6050; LI-COR, Lincoln, Neb.). Stomatal conductance (Gw) and leaf water losses (TR) were measured on five leaves from five different plants. Leaf water potential $(\psi)$ was measured immediately after gas exchange and in the same leaves after they were detached, with a pressure chamber (model 3005; Soilmoisture, Santa Barbara, Calif.). Root hydraulic resistance $(\mathrm{Rh})$ was measured in five lateral roots of similar shape from five different plants, with the same pressure chamber, according to Ramos and Kaufmann (1979).

A SPAD chlorophyll meter (model 502; Minolta) was used to 
measure chlorophyll concentration (Monje and Bugbee, 1992). The relative units were previously calibrated measuring chlorophyll concentration by shaking fresh leaf discs in $N, N$ dimethylformamide (Porra et al., 1989).

Canopy radiance was detected with a narrow-band width visible/near-infrared spectroradiometer fitted with $15^{\circ}$ field of view optics (SE590, CE390WB-R; Spectron Engineering, Denver) and expressed as spectral reflectance after standardization by radiance of a leveled white panel (Spectralon; Labsphere, North Sutton, N.H.). All spectral measurements were made in a nadir orientation with the radiometer held at arm's length. The distance between spectroradiometer and plant was $0.75 \mathrm{~m}$, allowing radiance measurements of a 0.20 -m-dimeter area of the plant. Four scans at a time were averaged in every measurement. Spectral measurements were made at the same time as gas exchange measurements on five randomly selected plants.

Hormonal detemination. Hormonal levels of ABA and cytofinins $(\mathrm{CK})$ were measured on $0.2 \mathrm{~g}$ freeze-dried leaf and root tissues (Olivella and Savé, 1993, 1994). The extraction and separation were made according Vine et al. (1987), purification was made by high-performace liquid chromatography, and hormonal content was determined by enzyme-linked immunosorbent assay (ELISA) according to Maldiney et al. (1986).

\section{Results and Discussion}

Table 1 shows the effects of low temperatures on plant water relations in gerbera. After 1 night at $5 \mathrm{C}$, root hydraulic resistance increased significantly without any change in stomatal conductance, leaf water loss and leaf water potential. Three nights at low temperature induced a decrease in leaf water potential and an increase in the near infrared reflectice (NIR) and red reflectance (Fig. 1) compared to values obtained after 1 night at low temperature.

The increase in root hydraulic resistance at low temperature could be caused by a decrease in membrane permeability to water (Ramos and Kaufmann, 1979; Markhart et al., 1979) or an increase in soil water viscosity (Terradas and Savé, 1992). The significant decrease in leaf water potential after 3 nights could have been caused by leaf water loss exceeding water uptake (Tranquillini, 1982). Although the chilling treatment of the present study promoted drought stress, as shown by the measured changes in leaf water potential and root hydraulic resistance, stomatal conduc-

Table 1. Chilling effects on root hydraulic resistance, $\mathrm{Rh}\left(\mathrm{MPa} \cdot \mathrm{cm}^{-2} \cdot \mathrm{s} 10^{4}\right)$, leaf water potential, $(\mathrm{MPa})$, stomatal conductance, Gs $\left(\mathrm{mmol} \cdot \mathrm{m}^{-2} \cdot \mathrm{s}^{-1}\right)$, and leaf water losses, TR $\left(\mathrm{mmnol} \cdot \mathrm{m}^{-2} \cdot \mathrm{s}^{-1}\right)$, of gerbera plants. Each value is the mean of five observations \pm standard error. Mean separation within colunms at $P \leq 0.05$.

\begin{tabular}{lcccc}
\hline & Rh & $\psi$ & Gs & TR \\
\hline Day 0 (control) & $2.20 \pm 0.67 \mathrm{a}$ & $-0.68 \pm 0.01 \mathrm{a}$ & $193.3 \pm 13.3 \mathrm{a}$ & $166.7 \pm 17.6 \mathrm{a}$ \\
Day 1 (1 night at 5C) & $3.87 \pm 0.88 \mathrm{~b}$ & $-0.65 \pm 0.02 \mathrm{a}$ & $2.49 \pm 0.16 \mathrm{ab}$ \\
Day 3 (3 nights at 5C) & $4.39 \pm 0.99 \mathrm{~b}$ & $-0.78 \pm 0.01 \mathrm{~b}$ & $213.3 \pm 29.1 \mathrm{a}$ & $1.76 \pm 0.10 \mathrm{a}$ \\
Day 7 (recovery) & $2.85 \pm 0.64 \mathrm{ab}$ & $-0.74 \pm 0.01 \mathrm{~b}$ & $190.0 \pm 17.3 \mathrm{a}$ & $1.83 \pm 0.19 \mathrm{a}$ \\
\hline
\end{tabular}

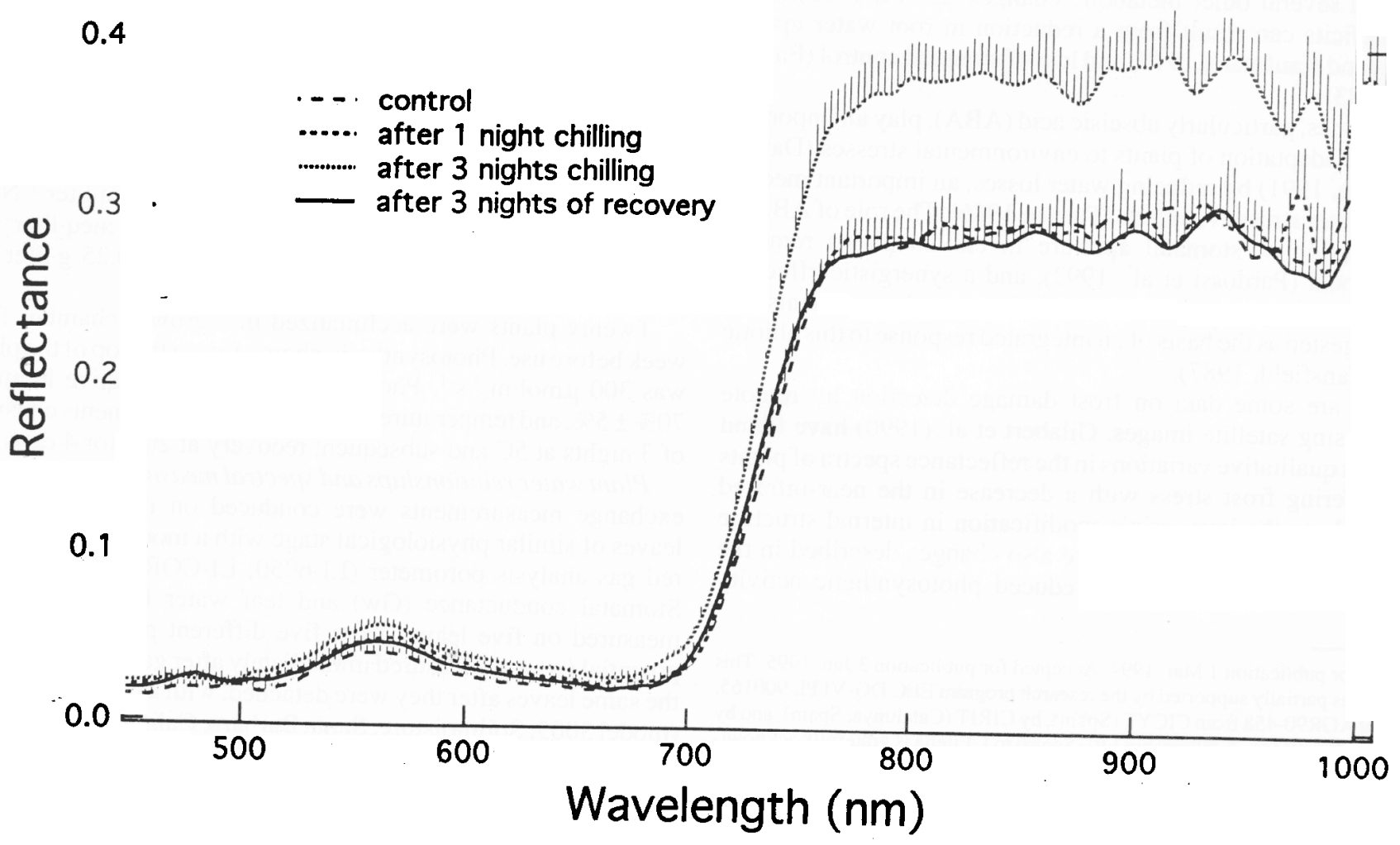

Fig. 1. Spectral reflectance of gerbera plants submitted to a chilling stress cycle. Bars are SEM $(n=5)$. 


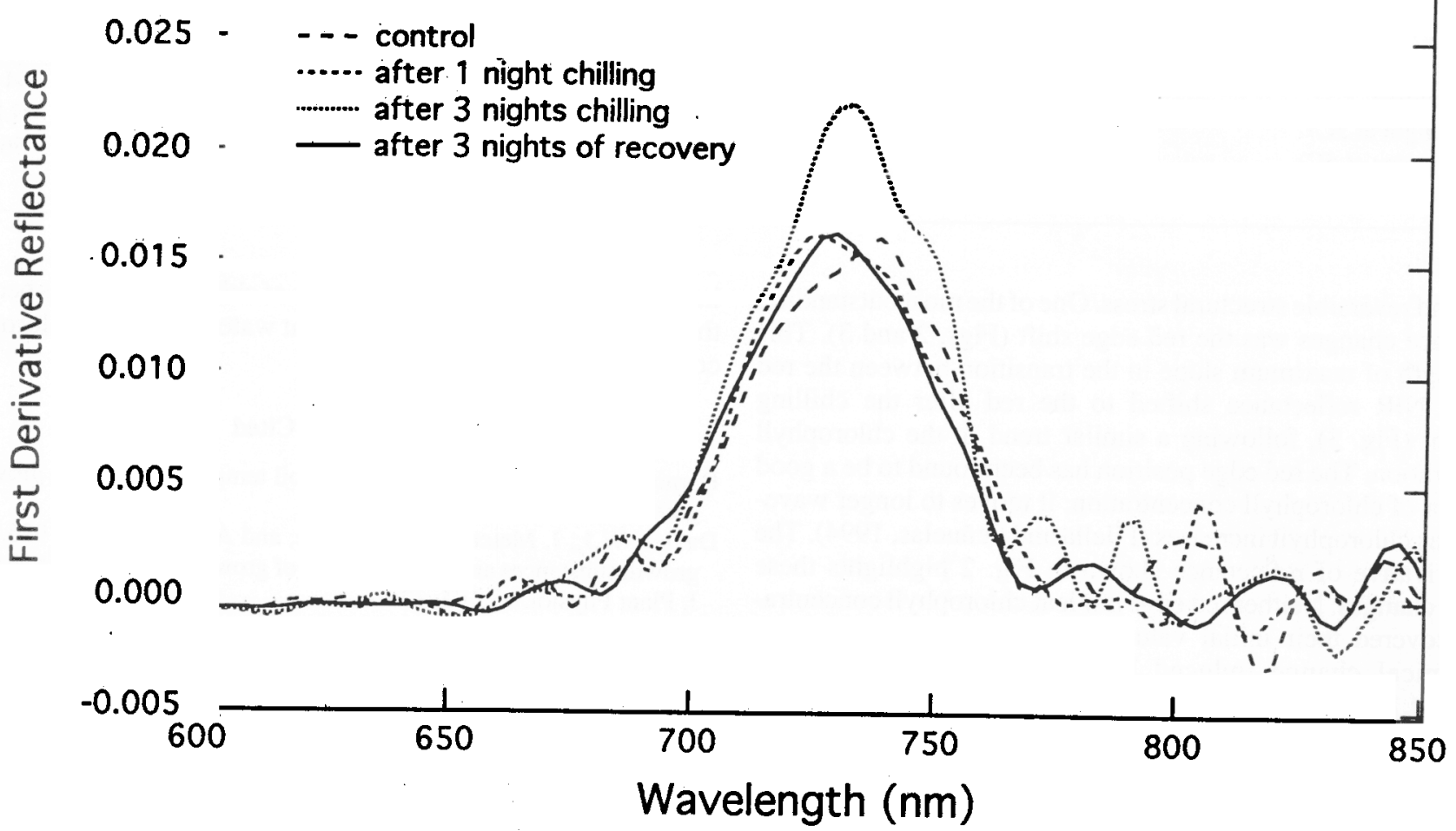

Fig. 2. First derivative mean reflectance spectra of the red edge region for the studied gerbera plants.

tance and leaf water loss did not change (Table 1 ). These results are in accordance with those of Eamus et al. (1983) and Eamus and Wilson (1984), who found that leaves of Phaseolus vulgaris $L$. and Pisum sativum L. maintained open stomata throughout chilling despite severe wilting.

After 4 days at 20C, root hydraulic resistance and NIR reflectance, but not leaf water potential, returned to their initial values, which could indicate that factors other than leaf water potential controlled the leaf water balance (Mansfield, 1987; Sinclair et al.,
1971; Trejo and Davies, 1991). The NIR reflectance increase observed after the 3rd night of chilling (Fig. 1) could be caused by this water deficit, which sometimes alters cell structure and chemistry (Gausman, 1974). Thus, NIR reflectance did not decrease as has been found in the same species affected by drought water deficits (Peñuelas et al., 1993) or in other species submitted to continuous severe freezing temperatures (Gilabert et al., 1990). The spectral reflectance changes found in this experiment, with a recovery of NIR reflectance after 4 days at 20C, seem to indicate

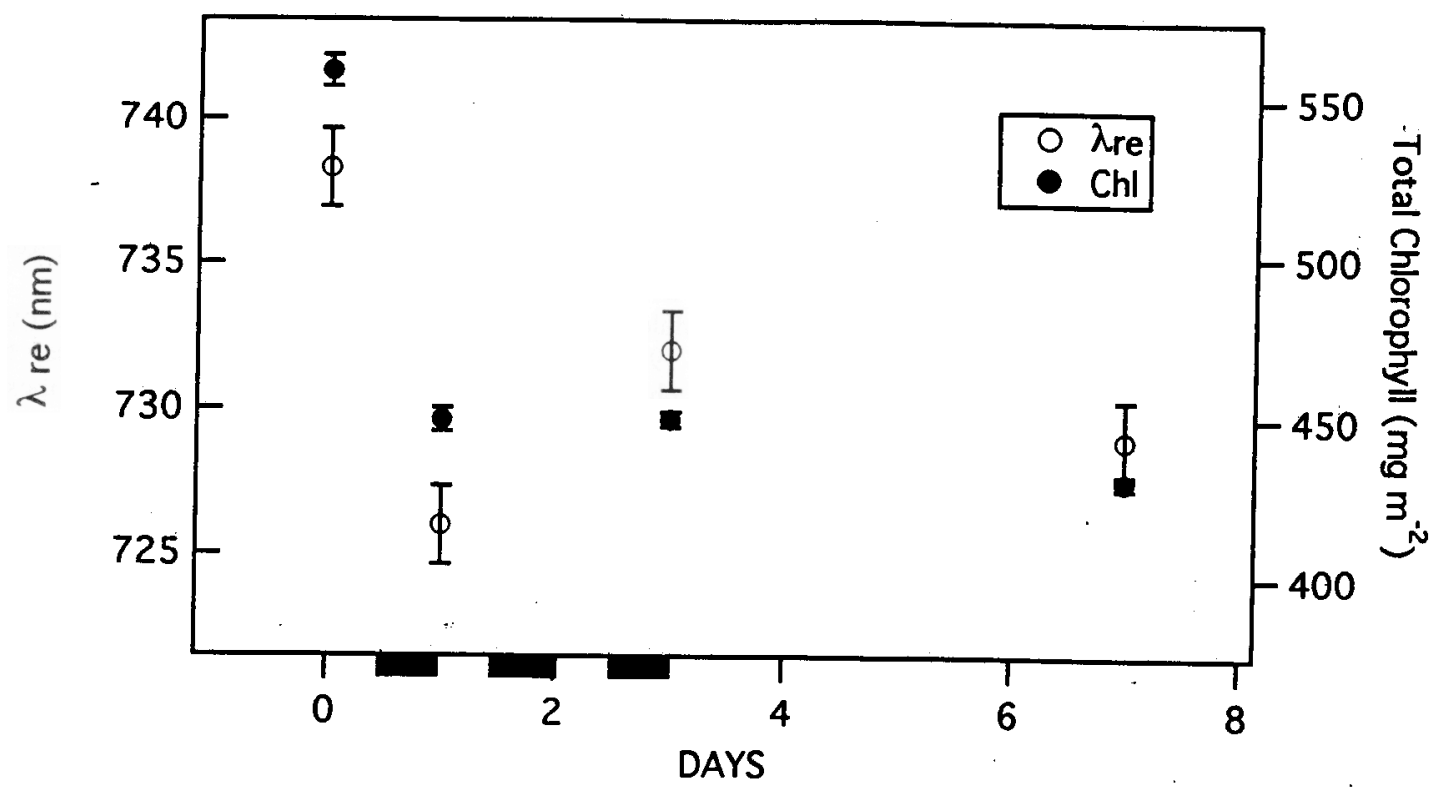

Fig. 3. Red edge wavelength $(\lambda$ re $)$ and leaf chlorophyll concentration of the gerbera plants throughout the chilling stress cycle. Bars are sEM $(n=5)$. Black wide lines show the night chilling period. 
Table 2. Chilling effects on content of abscisic acid (ABA) (pmol. $\mathrm{g}^{-1}$ dry weight) and cytokinins (CK) (pmol. $\mathrm{g}^{-1}$ dry weight) in roots and leaves of gerbera plants. Each value is the mean of three observations \pm standard error. Mean separation within columns at $P \leq 0.05$.

\begin{tabular}{lccc}
\hline \hline & \multicolumn{2}{c}{ A B A } & C K \\
\cline { 2 - 4 } Treatment & Leaves & Roots & Leaves \\
\hline Day 0 (control) & $862 \pm 111 \mathrm{~b}$ & $567 \pm 182 \mathrm{a}$ & $235 \pm 11 \mathrm{~b}$ \\
Day 1 (1 night at 5C) & $1277 \pm 26 \mathrm{c}$ & $555 \pm 129 \mathrm{a}$ & $56 \pm 29 \mathrm{a}$ \\
Day 3 (3 nights at 5C) & $901 \pm 364 \mathrm{bc}$ & $354 \pm 81 \mathrm{a}$ & $34 \pm /$ \\
Day 7 (recovery) & $391 \pm 24 \mathrm{a}$ & $546 \pm 265 \mathrm{a}$ & $24.8 \pm /$ \\
\hline
\end{tabular}

a mild and reversible structural stress. One of the most outstanding reflectance changes was the red edge shift (Figs. 2 and 3). This wavelength of maximum slope in the transition between the red and the NIR reflectance shifted to the red after the chilling treatment (Fig. 3), following a similar trend in the chlorophyll concentration. The red edge position has been found to be a good estimator of chlorophyll concentration: it moves to longer wavelengths as chlorophyll increases (Filella and Peñuelas, 1994). The first derivative of reflectance shown in Fig. 2 highlights these spectral changes. Neither red edge nor leaf chlorophyll concentration recovered their initial values, thus showing a significant biochemical change induced by the chilling temperatures (Markhart,1986). The reason for the drop in chlorophyll concentration in plants submitted to low temperatures seems to be the photooxidative damage to the membranes of the chloroplast thylakoids (Levitt, 1980).

Fluctuations of $\mathrm{ABA}$ and $\mathrm{CK}$ levels during the temperature stress cycle are shown in Table 2 . The high variability may be attributed to the variability of the plant material and the variability associated to ELISA (Neales et al., 1989; Norman et al., 1990; Sutula et al., 1986). Leaf ABA content increased immediately after 1 night at low temperature, did not change in plants chilled for 3 days and decreased markedly in recovered plants. The reported increase in leaf $\mathrm{ABA}$ content occurred before leaf water potential decreased. This leaf ABA biosynthesis is important during chilling stress to increase the plant tolerance to chilling stress (Lee et al., 1993). In contrast, root ABA level remained constant during the entire temperature stress cycle. This contrasts with reports by other authors (Pardossi et al., 1992; Zhang et al., 1986) that ABA increased in roots during low temperature stress and could have increased the hydraulic conductivity of the plants. Our results showed that resistance to water flow in roots increased during chilling stress, which could be partially attributable to ABA accumulation.

CK levels decreased in leaves and roots with decreasing temperature, and leaf CK reattained the initial values in the recovered plants. Reduction in CK content could be caused by a chillinginduced reduction in de novo synthesis and transport from the roots to the leaves (Mansfield, 1987).

Leaf water losses showed a higher significant relationship with ABA: CK ratio $(r=-0.8258, P \leq 0.05)$. ABA and CK may have acted as synergistic signals to the leaves of the physiological status of the plant when subjected to low temperature, similarly to the situation-described for drought stress (Davies et al., 1986; Davies and Zhang, 1991). This suggests that the variation in endogenous concentrations of different plant growth regulators may act to modulate plant water balance ( Davies et al., 1987).

In the variety of gerbera studied, chilling temperatures produced only a reversible strain and the plants otherwise remained uninjured. Thus, this variety may be cultured with low energetic inputs under Mediterranean conditions. Furthermore, changes in spectroradiometric signals, as NIR reflectance or red edge, may be indicators of the physiological status of chilled plant status because they correlated with changes in plant water status and chlorophyll concentration.

\section{Literature Cited}

Berniger, E. 1979. Effects of air and soil temperatures on the growth of gerbera. Sci. Hort. 10:271-276.

Davies, W.J., J. Metcalfe, T.A. Lodge, and A.R. da Costa. 1986. Plant growth substances and the regulation of growth under drought. Austral. J. Plant Physiol. 13:105-125.

Davies, W.J., A.R. da Costa, and T.A. Lodge. 1987. Water relations and plant growth regulators. In: S.S. Purohit (ed.). Hormonal regulation of plant growth and development. vol. 2. Martinus Nijhoff Publishers. Dordrech.

Davies, W.J. and J. Zhang. 1991. Root signals and regulation of growth and development of plants in drying soil. Annu. Rev. Plant Mol. Biol. 42:55-76.

Eamus, D., R. Fenton, and J.M. Wilson. 1983. Stomatal behaviour and water relations of chilled Phaseolus vulgaris L. and Pisum sativum L. J. Expt. Bet. 34:434441.

Eamus, D. and J.M. Wilson. 1984. A model for the interaction of low temperature, $\mathrm{ABA}, \mathrm{IAA}$, and $\mathrm{CO}_{2}$ in the control of stomatal behaviour. J. Expt. Bot. 35:91-98.

Filella, I. and J. Peñuelas. 1994. The red edge position and shape as indicators of plant chlorophyll content, biomass and hydric status. Intl. J. Remote Sensing 15(7): 1459-1470.

Gausman, H.W. 1974. Leaf reflectance of near infrared Photogammetric Eng. 40:183-191.

Gilabert, M. A., D. Segarra, and J. Meliá. 1990. A simplified algorithm for the evaluation of frost-affected citrus, p. 273-286. In: M.D. Steven and J.A. Clark (eds.). Applications of remote sensing in agriculture. Butterworths, London.

Lee, T. M., H.S. Lur, and C. Chu. 1993. Role of abscisic acid in chilling tolerance of rice (Oryza sativa L.). I. Endogenous abscisic acid levels. Plant Cell Environ. 16:481-490.

Levitt, J. 1980. Responses of plants to environmental stresses. vol. 1. Academic Press, New York. p. 23-64.

Lyons, J.M. 1973. Chilling injury in plants. Annu. Rev. Plant Physiol. 24:445-466.

Maldiney, R., F. Pelese, G. Palate, B. Sotta, L. Sossountzov, and E. Miginiac. 1986. A biotin-avidin-based enzyme immunoassay to quantify three phytohormones: Auxin, abscisic acid and zeatin-riboside. J. Immunol. Methods 90:151-158.

Mansfield, T.A. 1987. Hormones as regulators of water balance, p. 411430. In: P.J. Davies (ed.). Plant hormones and their role in plant growth and development. Martinus Nijhoff Publishers, Dordrecht.

Markhart, III, A.H. 1986. Chilling injury: A review of possible causes. HortScience 21:1329-1333.

Monje, O.A. and B. Bugbee. 1992. Inherent limitations of nondestructive chlorophyll meters. A comparison of two types of meters. HortScience 27:69-71.

Neales, T.F., A. Masia, J. Zhang, and W.J. Davies. 1989: The effects of partially drying part of the root system of Helianthus annuus on the abscicis acid content of the roots, xylem sap and leaves. J. Expt. Bet. 40(219):1113-1120.

Norman, S.M., V.P. Maier, and D.L. Pen. 1990. Abscisic acid accumula- 
tion and carotenoid and chlorophyll content in relation to water stress and leaf age of different types of citrus. J. Agr. Food Chem. 38:1326-34. Olivella, C. and R. Savé. 1993. Effects of moderate substrate drought stress on water relations and hormonal content in two cultivars of gerbera. In Environmental constraints in protected cultivation: possibilities for new growing techniques and crops. EEC Rpt. EUR 15123.

Olivella, C. and R. Savé. 1994. Niveles hormonales en hojas de gerbera de distinta edad. Proc. IV Symp. Metabolism y Modo de Acción de Fitohormonas. Soc. Esp. Fisio. Veg. (SEFV), Valencia, Spain.

Pardossi, A., P. Vemieri, and F. Tognoni. 1992. Involvement of ABA in regulating water status in Phaseolus vulgaris L. during chilling. Plant Physiol. 100:1243-1250.

Peñuelas, J., I. Filella, C. Biel, L. Serrano, and R. Savé. 1993. The reflectance at the $950-970 \mathrm{~nm}$ region as an indicator of plant water status. Intl. J. Remote Sensing 14:1887-1905.

Porra, R. J., W.A. Thompson, and P.E. Kriedemann. 1989. Determination of accurate extintion coefficients and simultaneous equations for assaying chlorophylls $\mathrm{a}$ and $\mathrm{b}$ extracted with four different solvents: Verification of the concentration of chlorophyll standards by atomic absorption spectroscopy. Biochimica el Biophysics Acts 975:384-394.

Ramos, C. and M.R. Kaufman. 1979. Hydraulic resistance of rough lemon roots. Physiol. Plant. 45:311-3 14.

Savé, R. and J. Matas. 1990. Gerbera sensitivity to chilling and freezing stress. Physiol. Plant. 79:A107.

Savé, R., P. Vendrell, L. Perez-Aranda, and L. Alegre. 1992. Low temperature effects on chlorophyll fluorescence and plant water relations in gerbera. Physiol. Plant. 85:A78.
Schanda, E. 1986. Physical fundamentals of remote sensing. SpringerVerlag, Berlin.

Sinclair, T.R., R.M. Hoffer, and M.M. Schreiber. 1971. Reflectance and internal structure of leaves from several crops during the growing season. Agron. J. 63:864-868.

Sutula, L., J.M. Gillet, S.M. Morrissey, and D.C. Ramsdell. 1986: Interpreting ELISA data and establishing the positive-negative threshold Plant Dis. 70(8):722-726.

Terradas, J and R. Savé. 1992. The influence of summer and winter stress and water relationships on the distribution of Quercus ilex L. Vegetatio 99-100:137-145.

Tranquillini, W. 1982. Frost-drought and its ecological significance, p. 379-400. In: O.L. Lange, P.S. Nobel, C.R. Osmond, and H. Ziegler (eds.). Encyclopedia of plant physiology. N.S. vol 12B. Physiological plant ecology II. Springer-Verlag, Berlin.

Trejo, C.L. and W.J. Davies. 1991. Drought-induced closure of Phaseolus vulgaris $L$. stomata precedes leaf water deficit and any increase in xylem ABA concentration. J. Expt. Bot. 42:1507-1515.

Turner, N.C. 1986. Adaptation to water deficits: A changing perspective. Austral. J. Plant Physiol. 13:175-190.

Vine, J. H., D. Noiton, J.A. Plummer, C. Baleriola-Lucas, and G. Mullins. 1987. Simultaneous quantitation of indole 3 -acetic acid and abscisic acid in small samples of plant tissue by gas chromatography/mass spectrometry/selected ion monitoring. Plant Physiol. 85:419422.

Zhang, C. L., P.H. Li, and M.L. Brenner. 1986. Relationship between mefluidide treatment and abscisic acid metabolism in chilled corn leaves. Plant Physiol. 81:699-701. 